\title{
ARTICLE
}

\section{Radiation Protection Study for the J-PARC Neutrino Experimental Facility}

\author{
Masayuki HAGIWARA $^{1 *}$, Kazutoshi TAKAHASHI ${ }^{1}$, Asako TAKAHASHI ${ }^{1}$, Taichi MIURA ${ }^{1}$, Atsushi KANAI $^{2}$ \\ Fuyuki KOUNO ${ }^{2}$, Yuichi OYAMA ${ }^{1}$, Taku ISHIDA $^{1}$ and Yoshikazu YAMADA ${ }^{1}$ \\ ${ }^{1}$ High Energy Accelerator Research Organization, KEK \\ 1-1, Oho, Tsukuba, Ibaraki 305-0801, Japan \\ ${ }^{2}$ Toyko Nuclear Service Co., Ltd, \\ 2-4 Shirakata Shirane, Tokai-mura, Naka-gun, Ibaraki, 319-1195 Japan
}

\begin{abstract}
The characteristics of radiation and radioactivity in the Japan Proton Accelerator Research Complex (J-PAR C) neutrino experimental facility have been investigated under the $30-\mathrm{GeV}$ proton beam operation below $145 \mathrm{k}$ $\mathrm{W}$ in order to estimate the maintenance scenario and the environmental impact for the future high power op eration up to $750 \mathrm{~kW}$. The radioactivity produced in the magnetic horn cooling water and helium gas in the helium vessel which were installed around the target and the concrete and soil behind the beam dump has $b$ een measured in relation to the beam power. These activity concentrations under the high power operation ( 750 $\mathrm{kW}$ for 20 days) are estimated from the measured results to be up to two hundred times of the regulation value for the disposal in Japan. The depth profiles of the radioactivity produced in the concretes behind the beam dump show constant distributions on the beam axis, while those at off-beam axis show exponential att enuation with increasing the concrete depth.
\end{abstract}

\section{KEYWORDS: radioactivity, high energy, neutron, muon, tritium, concrete, soil, helium gas}

\section{Introduction}

The J-PARC neutrino experiment is a second generation long-baseline neutrino-oscillation experiment to study nature of neutrinos. ${ }^{1)}$ Artificial neutrino beam generated in the Japan Proton Accelerator Research Complex (J-PARC) ${ }^{2)}$ located at Tokai, Ibaraki, Japan is shoot toward the 50 kton water Cherenkov detector, Super-Kamiomande, which is located about $1000 \mathrm{~m}$ underground in Kamioka mine (Gifu) and is $295 \mathrm{~km}$ away from Tokai. In the J-PARC neutrino experimental facility, the neutrino beam is produced from the decay of charged pions that have been produced in high-energy proton interactions on a graphite target. The produced pions focused toward Super-Kamiomande detector (SK) using three troidal magnetic horns (hereafter referred to as horns) are decayed as e.g. $\pi^{+} \rightarrow \mu^{+}+v_{\mu}$ in the 96-m-long decay volume filled with helium gas. The experiment starts in January 2010. The beam power was continuously increased and reached $145 \mathrm{~kW}$ until March 11th 2011. The primary goal of the J-PARC neutrino experimental facility is to perform stable operation with $750 \mathrm{~kW}$ proton beam, the intensity of which is 100 times higher than that used in K2K experiments performed at Tsukuba (KEK) and Kamioka from 1999 to $2001^{3)}$, in order to produce intense neutrino beams toward the SK.

On the other hand, the high-intensity proton beam simultaneously produces a number of secondary particles such as neutrons, protons, pions, and muons, and then these

\footnotetext{
*Corresponding Author, E-mail:masayuki.hagiwara@kek.jp C 2012 Atomic Energy Society of Japan, All Rights Reserved.
}

particles severely activate the accelerator components such as the target, horns and their cooling water, helium gas in the decay volume and beam dump. Especially, radioactivity such as ${ }^{3} \mathrm{H}$ produced in the cooling water and helium gas in the decay volume will be of grave concern, because the radioactivity will be release to environments for maintenance of the cooling system and horns. The radioactivity production in the earth behind the beam dump is another concern, because the earth behind the beam dump can be irradiated by high-energy muons produced from the pion decay together with neutrinos. These radiation and radioactivity induced in the neutrino experimental facility should be investigated under the low-power beam operation in order to estimate the maintenance scenario and the environmental impact due to the future high power operation up to $750 \mathrm{~kW}$, although the facility have been designed using past experimental data of KEK proton synchrotron and MARS simulation code ${ }^{3-4)}$.

In this study, the radioactivity of nuclides $\left({ }^{3} \mathrm{H},{ }^{7} \mathrm{Be}\right.$ and etc.) produced in the cooling water for the horns, helium gas in the helium vessel, concrete and soil behind the beam dump were measured in relation to the beam power using $30-\mathrm{GeV}$ proton beam below $145 \mathrm{~kW}$. The radioactivity induced by the $750 \mathrm{~kW}$ beam operation is estimated from the measured results

\section{J-PARC neutrino experimental facility}

The J-PARC neutrino experimental facility consists of three sections: the target station, decay volume and beam dump as shown in Figure 1. Produced pions decay in flight 


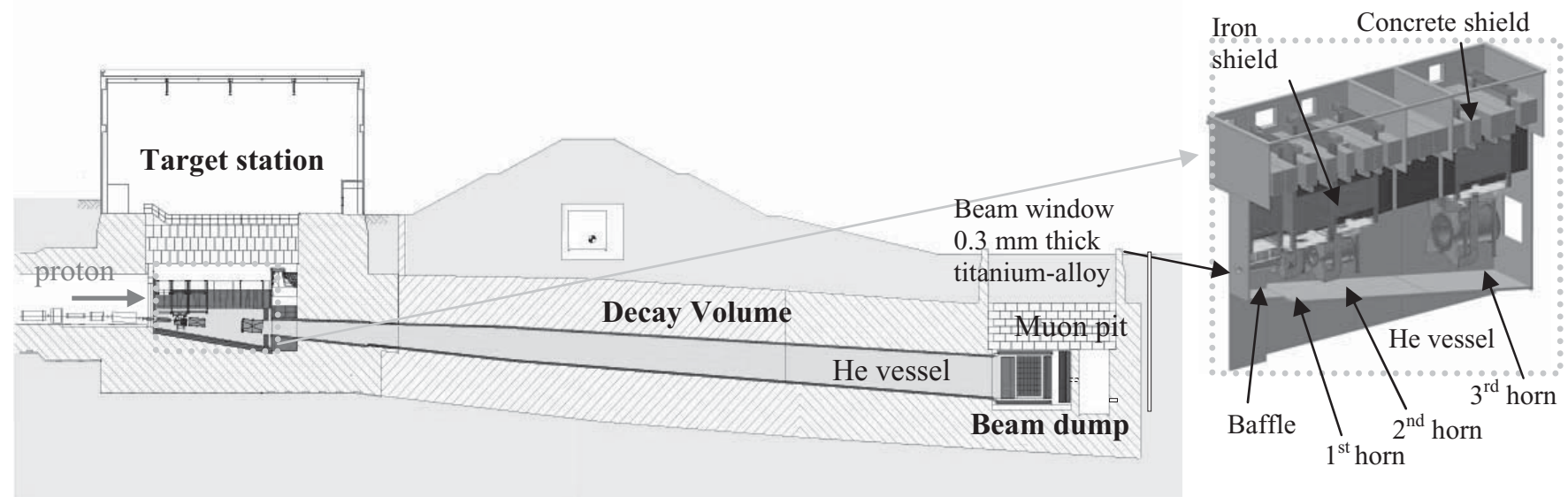

Fig. 1 Longitudinal sectional view of the neutrino experimental facility on the beam axis.

inside a single steel vessel filled with helium gas (1 atm, $\sim 1500 \mathrm{~m}^{3}$ ), which is called helium vessel, to reduce pion absorption and to suppress tritium and NOx production by the beam. The helium vessel is separated from the primary beamline by a beam window at the upstream end in target station, and is connected to the decay volume at the downstream end. The helium vessel contains the target, three horns, the beam dump and $2 \mathrm{~m}$ thick iron shield and $1 \mathrm{~m}$ thick concrete shield above the horns. The target is a 91.4-cm-long, 2.6- $\mathrm{cm}$ diameter graphite rod with density of $1.8 \mathrm{~g} / \mathrm{cm}^{3}$ and is located in the first horn to collect pions generated at the target. The second and third horns are used to focus the pions toward the downstream decay volume. The three horns consist of two coaxial (inner and outer) conductors made of aluminum alloy (JIS standard number: 6061-T6), which encompass a closed volume. In the closed volume inside the conductor of the horns, cooling water is sprayed to chill the conductor excited by a $250 \mathrm{kA}$ current pulse.

The decay volume is a $\sim 96 \mathrm{~m}$ long steel tunnel. The cross section is $1.4 \mathrm{~m}$ wide and $1.7 \mathrm{~m}$ high at the upstream end, and $3.0 \mathrm{~m}$ wide and $5.0 \mathrm{~m}$ high at the downstream end.

The beam dump is installed at the end of the decay volume in order to absorb survived hadrons. The beam dump's core is made of $3.17 \mathrm{~m}$-long, $1.94 \mathrm{~m}$-wide and $4.69 \mathrm{~m}$-high graphite with density of $1.7 \mathrm{~g} / \mathrm{cm}^{3}$. Iron plates with the total thickness of $2.4 \mathrm{~m}$ are placed at the downstream end of the graphite core. Muons above $\sim 5.0 \mathrm{GeV} / \mathrm{c}$ can go through the beam dump to reach the downstream muon pit in which the distribution profile of muons is measured to monitor the neutrino beam intensity and direction.

\section{Experiments}

\section{Radioactivity in the horn cooling water}

The cooling water which are sprayed inside the conductor of the horns was pumped up and circulated in the three horns, cooling pipes, a heat exchanger and $0.9 \mathrm{~m}^{3}$ surge tank (SUS) at the flow rate of $160 \mathrm{~L} / \mathrm{min}$ in the cooling loop system. Total amount of the cooling water was $2.7 \mathrm{~m}^{3}$. The cooling water was replaced with new pure water from the surge tank after each physics run of $7-20$ day beam operation. The old cooling water was released to the enviroment after dilution and demineraliztion with an ion exchanger to be less than the regulation value of disposal in Japan and municipality. Prior to the enviromental release, the cooling water was sampled with a $500 \mathrm{~mL}$ polyethylene container for the measurements of the radioactivity. The $\gamma$-ray activity in the sampling water was measured by using a high purity germanium detector. The counting efficiency was determined using a mixed $\gamma$-ray source in the same volume as the sampling container. The ${ }^{3} \mathrm{H}$ activities of the sampling water were measured with a low background-type liquid scintillation counter, after a fraction of sampling water $(1 \mathrm{~mL})$ was mixed with $14 \mathrm{~mL}$ liquid scintillator.

\section{Radioactivity in helium gas in the helium vessel}

The hellium gas in the hellium vessel was sampled after several physics runs using a $1 \mathrm{~L}$ glass container which was evacuated prior to sampling. ${ }^{3} \mathrm{H}$ in the sampling gas was collected in cold traps under the Ar-gas flow rate of 0.2 $\mathrm{L} / \mathrm{min}$, for 30 minutes. In order to indentify the chemical composition of ${ }^{3} \mathrm{H}$ (HT, HTO) in the hellium gas, we put cold traps before/after an oxidation catalyst of $\mathrm{Pd}_{-} \mathrm{Al}_{2} \mathrm{O}_{3}$. The each trap was separated into two glass tubes to confirm the collection efficiency. The ${ }^{3} \mathrm{H}$ activities of the samples were measured with a low background-type liquid scintillation counter, after the fraction collected in the cold traps was mixed with $1 \mathrm{~mL}$ water and $20 \mathrm{~mL}$ liquid scintillator.

\section{Radioactivity in concrete and soil}

Figure 2 illustrates the experimental setup for the measurement of activity produced in the concrete and soil behind the beam dump. In order to obtain the spatial distributions of induced activities around beam dump, irradiation samples were set at three locations: A) for a concrete shield of off beam axis, B) for a concrete shield on the beam axis C) for soil on the beam axis. The concrete samples were prepared by boring horizontal holes in the concrete wall to depth of $1 \mathrm{~m}$ with diameters of 7 and $6 \mathrm{~cm}$ at the location A) and B), respectively. The bored concretes were pulverized and contained into 50-mm-diameter and 65 -mm-high plastic containers with the concrete weight of 
$\sim 150 \mathrm{~g}$ for the location A) and 35-mm-diameter and 85 -mm-high plastic containers with the concrete weight of $\sim 90 \mathrm{~g}$ for the location B) in order to measure the depth profiles. These concrete samples, which were stacked in the 1-m-long aluminum pipe with the wall thickness of $5 \mathrm{~mm}$ and top-and-bottom plate thicknesses of $25 \mathrm{~mm}$, were set back in the original locations. The soil sample were prepared by boring wells to depths of $\sim 20 \mathrm{~m}$ with diameter of $10 \mathrm{~cm}$ at the location $\mathrm{C}$ ) which was located $2 \mathrm{~m}$ behind the outside of concrete of the beam dump building. The soil samples were prepared by mixing $\sim 100 \mathrm{~g}$ dried soil and $\sim 25$ $\mathrm{g}$ groundwater with consideration of the environmental composition ratio and contained into the 50-mm-diameter and $65-\mathrm{mm}$-high plastic containers. These soil samples were stacked in a 1-m-long aluminum pipe and set back into the bored well to be sit on the Muon pit floor level. These samples were picked up after the beam operation with $3.4 \times 10^{19}$ protons hit on the target (p.o.t.)

The $\gamma$-ray activity in the samples was measured by using a high purity germanium detector. The counting efficiency was determined using the Canberra LabSOCS software program. $^{4,5)}$

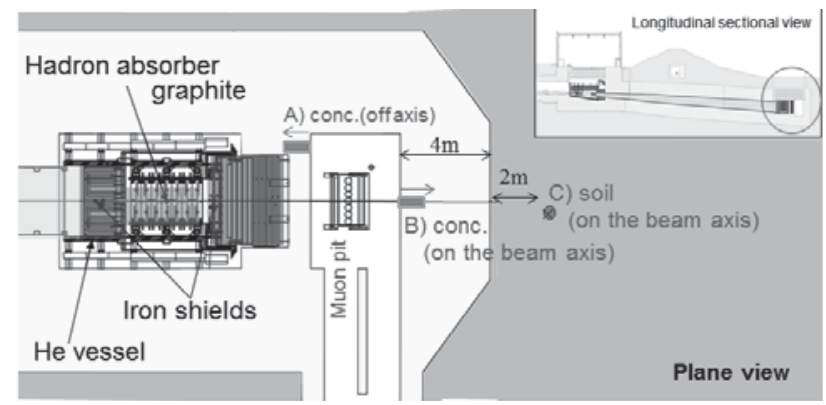

Fig. 2 Experimental setup for the measurement of activity produced in the concrete and soil behind the beam dump.

\section{Results}

\section{Radioactivity in the horn cooling water}

Figure 3 shows the results of radioactivity produced in the horn cooling water in relation to the beam power (number of proton hit on the target; p.o.t). ${ }^{3} \mathrm{H},{ }^{7} \mathrm{Be},{ }^{22} \mathrm{Na}$, ${ }^{54} \mathrm{Mn}$ and ${ }^{58} \mathrm{Co}$ were observed in the samples and these activitiy concentrations were well-fitted with a linear function of p.o.t. The production rates obtained from the fitting results are summerized in Table 1. The activities of ${ }^{3} \mathrm{H}$ and ${ }^{7} \mathrm{Be}$, which were mainly produced in the spalation reaction of oxygen in cooling water, show $\sim 1000$ times higher than that of the corrosion products $\left({ }^{22} \mathrm{Na},{ }^{54} \mathrm{Mn}\right.$ and ${ }^{58} \mathrm{Co}$ ) from structure materials in the horn cooling system such as the horn conductors (aluminum) and cooling pipes (stainless steels). The activity ratio of ${ }^{7} \mathrm{Be} /{ }^{3} \mathrm{H}$ is 6.3 . Considering the decay constants and the excitation functions of ${ }^{16} \mathrm{O}(\mathrm{p}, \mathrm{t})$ and ${ }^{16} \mathrm{O}\left(\mathrm{p},{ }^{7} \mathrm{Be}\right)$ reactions ${ }^{8)}$, the ratio is still low. Most of ${ }^{7} \mathrm{Be}$ activity would be adhered in the cooling system such as cooling pipes and a heat exchanger. The activity concentration and total activity produced under the $750 \mathrm{~kW}$ operation were estimated using the measured production rate as follows; ${ }^{3} \mathrm{H}\left(9.4 \mathrm{kBq} / \mathrm{cm}^{3}, 25.5 \mathrm{GBq}\right)$, ${ }^{7} \mathrm{Be}\left(60 \mathrm{kBq} / \mathrm{cm}^{3}, 161 \mathrm{GBq}\right),{ }^{22} \mathrm{Na}\left(8.5 \mathrm{~Bq} / \mathrm{cm}^{3}, 23 \mathrm{MBq}\right)$, ${ }^{54} \mathrm{Mn}\left(4.7 \mathrm{~Bq} / \mathrm{cm}^{3}, 13 \mathrm{MBq}\right)$ and ${ }^{58} \mathrm{Co}\left(9.9 \mathrm{~Bq} / \mathrm{cm}^{3}, 27 \mathrm{MBq}\right)$. The estimated activity of ${ }^{3} \mathrm{H}$ is $45 \%$ lower than the activity estimated from the past $\mathrm{K} 2 \mathrm{~K}$ experiments. However the concentration is 157 times higher than the regulation vaule for disposal in Japan $\left(60 \mathrm{~Bq} / \mathrm{cm}^{3}\right)$. The other activities are 4.7 200 times higher than regulation values for disposal. These activities should be removed by demineralizers and/or should be diluted for the enviromental release.

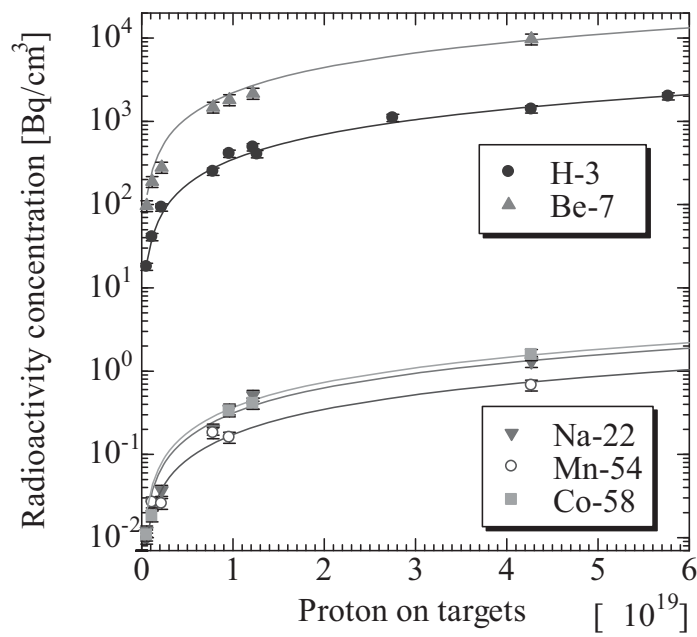

Fig. 3 Radioactivity $\left({ }^{3} \mathrm{H},{ }^{7} \mathrm{Be},{ }^{22} \mathrm{Na},{ }^{54} \mathrm{Mn}\right.$ and $\left.{ }^{58} \mathrm{Co}\right)$ produced in the horn cooling water in relation to the number of proton on target. The symbols indicate the experimental results. The line is the fitting results of the experimental results with a linear function.

Table 1 Production rates of radioactivity produced in the horn cooling water.

\begin{tabular}{|c|l|l|l|l|l|}
\hline & ${ }^{3} \mathrm{H}$ & ${ }^{7} \mathrm{Be}$ & ${ }^{22} \mathrm{Na}$ & ${ }^{54} \mathrm{Mn}$ & ${ }^{58} \mathrm{Co}$ \\
\hline $\begin{array}{c}\text { Activity } \\
\text { production } \\
\begin{array}{c}\text { rates } \\
{\left[\mathrm{Bq} / \mathrm{cm}^{3} / \mathrm{p}\right]}\end{array}\end{array}$ & $\begin{array}{l}3.5 \\
\times 10^{-17}\end{array}$ & $\begin{array}{l}2.2 \\
\times 10^{-16}\end{array}$ & $\begin{array}{l}3.1 \\
\times 10^{-20}\end{array}$ & $\begin{array}{l}1.7 \\
\times 10^{-20}\end{array}$ & $\begin{array}{l}3.7 \\
\times 10^{-20}\end{array}$ \\
\hline
\end{tabular}

\section{Radioactivity in helium gas in the helium vessel}

Figure 4 show the results of ${ }^{3} \mathrm{H}$ production from hellium gas in the hellim vessel. Most of the expermental data show good agreement with a simple estimation using an averaged cross section $(5 \mathrm{mb})$ of ${ }^{4} \mathrm{He}(\mathrm{p}, \mathrm{t})$ under the energies above $20 \mathrm{MeV}$ and the corresponding hadron flux calclated by the MARS code. On the other hand, the data of $4 \times 10^{19}$ p.o.t. show higher value than the expected data from the calculation. The discrepancy might come from the other sources of ${ }^{3} \mathrm{H}$ production such as water contained in the concrete shield and/or the moisture condensation in the hellium vessel, because the hellium vessel was opened to air for the maintenace in summer shutdown before the 
operation of $4 \times 10^{19}$ p.o.t. The continuous monitoring would be requred for the detail study. The activity concentration and total activity produced under the $750 \mathrm{~kW}$ (20 days) operation are estimated to be $1 \mathrm{~Bq} / \mathrm{cm}^{3}, 1.7 \mathrm{GBq}$ using the simulation value. The concentration is 201 times higher than the regulation vaule for disposal in Japan $\left(5 \mathrm{mBq} / \mathrm{cm}^{3}\right.$ under the three month average) and should be diluted for the enviromental release.

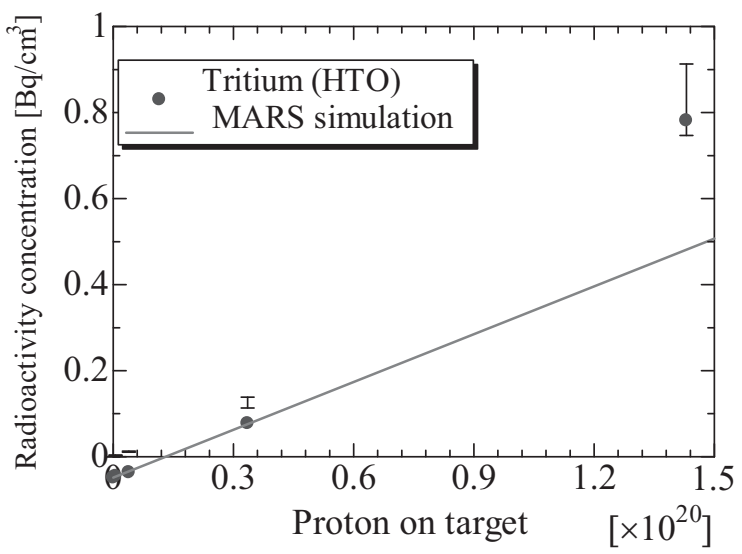

Fig. $4{ }^{3} \mathrm{H}$ produced in the helium vessel in relation to the number of proton on target. The symbols indicate the measured results. The line shows the result from the MARS calculation.

\section{Radioactivity in concrete and soil}

Figures 5 and $\mathbf{6}$ show the depth profiles of radioactivity produced in the concrete samples located at A) and B) shown in Figure 2, respectively. In the location A) which was off beam axis, ${ }^{7} \mathrm{Be},{ }^{22} \mathrm{Na},{ }^{46} \mathrm{Sc}$ and ${ }^{54} \mathrm{Mn}$ were observed in the all sample. These activities exponentially decrease with increasing the concrete depth. This trend is similar to that of concrete shields used in high-energy neutron fields. On the other hand, the depth profiles of ${ }^{22} \mathrm{Na},{ }^{46} \mathrm{Sc}$ and ${ }^{54} \mathrm{Mn}$ observed in the location B) on the beam axis, show constant distributions with respect to the concrete depth. This result may indicate the dominat particles which activated the conrete, were very high penetratable ones such as muons. In the location C) on the beam axis, ${ }^{54} \mathrm{Mn}$ are observed in the several soil samples. The averaged activitiy was $2.6 \pm 0.24 \mathrm{mBq} / \mathrm{g}$. The activity would be 7.7 times higer than the present values under the $750 \mathrm{~kW}(20$ days) operation.

\section{Summary}

The radioactivity produced in the horn cooling water, helium gas in the helium vessel, concrete and soil behind the beam dump was measured in relation to the beam power. These activity concentrations under the high power operation (750 kW, 20 days) were estimated from the measured results. The depth profiles of the radioactivity produced in the concretes on the beam axis showed constant distributions, while those at off-beam axis indicated exponential attenuation with increasing the concrete depth. We will continue these monitoring for further study.

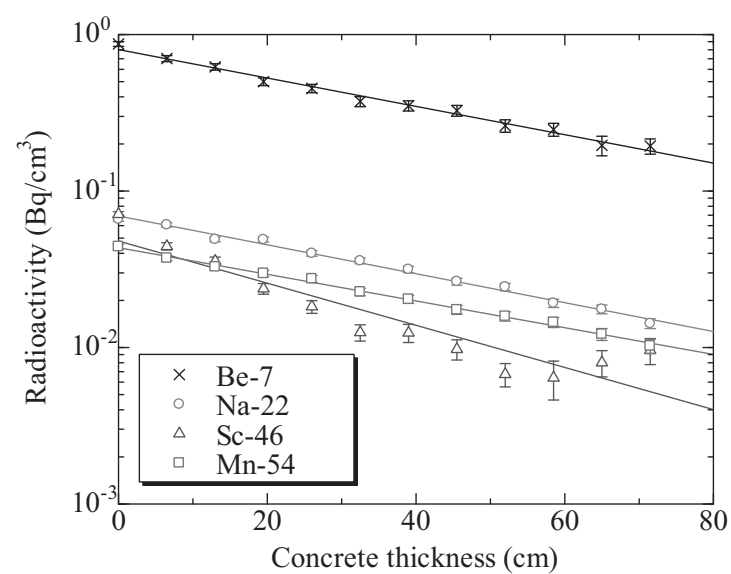

Fig. 5 Radioactivity $\left({ }^{7} \mathrm{Be},{ }^{22} \mathrm{Na},{ }^{46} \mathrm{Sc}\right.$ and $\left.{ }^{54} \mathrm{Mn}\right)$ produced in the off-beam axis concrete for the concrete depth. The symbols indicate the experimental results. The line is the fitting results with an exponential function.

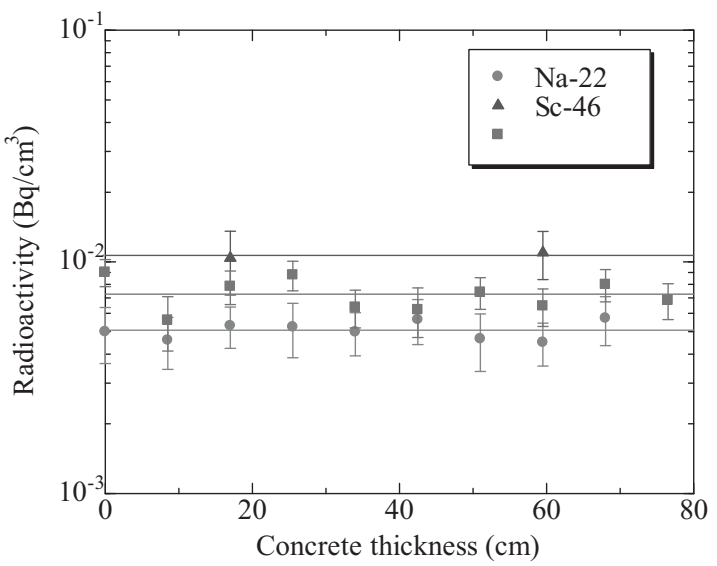

Fig. 6 Radioactivity $\left({ }^{22} \mathrm{Na},{ }^{46} \mathrm{Sc}{ }^{54} \mathrm{Mn}\right)$ produced in the concrete on the beam axis for the concrete depth. The symbols indicate the experimental results. The line is the fitting results with a constant function.

\section{References}

1) K. Abe, N. Abgrall, H. Aihara, et al., "The T2K experiment", Nucl. Instrum. Meth. A, In Press.

2) J-PARC TDR, KEK-Report2002-13 and JAERI-Tech 2003-044, http://hadron.kek.jp/accelerator/TDA/tdr2003/index2.htmlS, 2003

3) K2K Collaboration, M.H. Ahn, E. Aliu, et al., "Measurement of neutrino oscillation by the $\mathrm{K} 2 \mathrm{~K}$ experiment", Phys Rev D, 74[7], 072003 (2006).

4) Mokhov, N. V. The MARS code system user's guide. Fermilab-FN-628, Fermi National Accelerator Laboratory (1995).

5) Mokhov, N. V. Status of MARS code. Fermilab-Conf-03/053, Fermi National Accelerator Laboratory (2003). Available on http://www-ap.fnal.gov/MARS/

6) F. L.Bronson, J. Radioanal. Nucl. Chem., 255, 137 (2003).

7) R. Venkataraman, F. Bronson, V. Atrashkevich, M. Field, and B. M. Young, J. Radioanal. Nucl. Chem., 264, 213 (2005).

8) "EXFOR Database," National Nuclear Data Center; available on http://www.nndc.bnl.gov/ (2008) 